\title{
$\mathrm{T}$ \\ 1 опические антибактериальные препараты в терапии больных акне
}

А.Г. Пашинян ${ }^{1}$, А. А. Шахнович ${ }^{2}$

${ }^{1}$ ФГБОУ ВО «Российский национальный исследовательский медицинский университет им. Н.И. Пирогова» Минздрава России

117997, г. Москва, ул. Островитянова, д. 1

2 ФГБУ «Поликлиника № 5» Управления делами Президента Российской Федерации

119121, г. Москва, ул. Плющиха, д. 14

Освещены вопросы патогенеза акне, дана оценка эфрфективности и безопасности применения 1\% раствора

клиндамицина у пациентов с акне.

Ключевые слова: акне, патогенез, P.acnes, $1 \%$ раствор клиндамицина, топические антибактериальные

средства.

Контактная инсрормация: stsoagp@gmail.com. Вестник дерматологии и венерологии 2017; (1): 64—67.

\section{opical antibacterial medications for therapy of patient with acne}

A. G. Pashinjan ${ }^{1}$, A. A. Shahnovich ${ }^{2}$

${ }^{1}$ The Russian National Research Medical University named after N.I. Pirogov Ostrovityanova str., 1, Moscow, 117997, Russia

2 FGBU "Polyclinic № 5" Office of the President of the Russian Federation

Plyushchikha str., 14, Moscow, 119121, Russia

Problems of acne pathogenesis are reviewed. Efficacy evaluation and safety use of $1 \%$ clindamycin solution at patient with acne are demonstrated.

Key words: acne, pathogenesis, P. acnes, $1 \%$ clindamycin solution, topical antibacterial medications.

Corresponding author: stsoagp@gmail.com. Vestnik Dermatologii i Venerologii 2017; 1: 64—67. 
Угри обыкновенные (L70) - распространенное заболевание кожи, встречающееся у 70-80\% населения в возрасте до 21 года. По данным научных исследований, в настоящее время акне встречается у $51 \%$ женщин 20-24 лет, у 41-54\% женщин в возрасте 25-40 лет [1-3]. Частота тяжелых и среднетяжелых форм составляет 20-35\% от общей заболеваемости акне [2].

В Германии акне диагностируется у 64\% пациентов в возрасте от 20 до 29 лет и у $43 \%$ - в возрасте от 30 до 39 лет, в Австралии - у 93,3\% в возрасте 16-18 лет, в Бельгии и Китае - у 90\% подростков, в США - у 2,2-2,6\%, и каждый год регистрируется около 150000 новых случаев, в большинстве у пациентов моложе 30 лет [2, 4].

По современным представлениям акне является результатом развития нескольких взаимосвязанных патологических процессов: суперпродукции кожного сала, фолликулярного гиперкератоза, локального воспалительного процесса, индуцированного продуктами жизнедеятельности Propionibacterium acnes [5, 6].

Ведущая роль в патогенезе заболевания принадлежит предрасположенности к генетически обусловленной гиперандрогении, которая может проявляться повышением не только уровня гормонов, но и чувствительности рецепторов к нормальному или сниженному количеству андрогенов в организме $[7,8]$.

Гиперандрогения способствует увеличению объема кожного сала со снижением экспрессии фермента трансглутаминазы и концентрации незаменимой $\alpha$-линоленовой кислоты - регулятора дифференцировки кератиноцитов протока сально-волосяных фолликулов [7, 9].

Усиление тканевого действия андрогенов за счет увеличения в циркулирующей крови их свободных форм опосредуется влиянием инсулина на продукцию глобулина, который связывает половые гормоны, обусловливая гиперандрогенные состояния [7, 10], и клинически проявляется себореей, акне, гирсутизмом и андрогензависимой алопецией [11].

Ключевым звеном в патогенезе акне является фолликулярный гиперкератоз. Преобладание процессов пролиферации и дискератоза над десквамацией эпителия приводит к закрытию протока сально-волосяного фолликула и создает благоприятные анаэробные условия для размножения факультативных анаэробов $P$. acnes и $P$. granulosum $[5,12]$.

Несмотря на принадлежность данных бактерий к резидентам нормальной микрофлоры кожи, $P$. acnes продуцируют медиаторы воспаления, которые, в свою очередь, влияют на экспрессию антимикробных пептидов - $\beta$-дефенсинов, вырабатываемых эпителиальными клетками, провоспалительными цитокинами и бактериями [13]. Отмечаются увеличение относительной экспрессии $\beta$-дефенсина-2, лактоферрина, лизоцима, РНК-азы-7, подавление относительной экспрессии $\alpha$-дефенсина [14]. Важную роль в механизме фрормирования угрей играют кателицидины, толл-подобные рецепторы TLR-2, TLR-4, связывание которых действует как сигнал опасности и приводит к повышению бактерицидной активности фрагоцитов и способствует пролиферации Т-клеток [15].

В течение ряда лет считалось, что ведущими факторами, препятствующими колонизации поверхности кожи микроорганизмами, являются низкое содержание воды и наличие так называемой кислотной мантии Маркионини [16]. На сегодняшний день представляется очевидным, что антимикробные пептиды формируют химический щит на поверхности кожи, участвуют в координации многочисленных компонентов врожденной и адаптивной иммунной системы [17].

При выборе терапии пациентов с акне необходимо учитывать тип кожи, пол, возраст, сопутствующие заболевания, эффрективность предшествующих методов лечения. Назначаемые препараты должны влиять на $P$. acnes и воспаление, способствовать снижению повышенной секреции кожного сала, нормализовать цикл ороговения клеток и уровень андрогенов.

Наружная терапия является обязательным компонентом лечения акне разной степени тяжести $[18,19]$.

В соответствии с рекомендациями EADV, Федеральными клиническими рекомендациями Российского общества дерматовенерологов и косметологов (2015) при легком течении акне с преобладанием комедонов показаны топические ретиноиды, при наличии папуло-пустулезных высыпаний - топические ретиноиды в сочетании с топическими антибиотиками и/или бензоила пероксидом [19-21].

Учитывая возможную резистентность $P$. acne к антибактериальным препаратам, следует руководствоваться следующими принципами лечения: комбинировать топические антибиотики с топическими ретиноидами или с бензоила пероксидом; избегать кратковременного назначения наружной антибиотикотерапии; не использовать одновременно топические и системные антибиотики разных групп [21].

Одним из эффрективных топических препаратов, применяемых для лечения папуло-пустулезных акне легкой и среднетяжелой степени, является клиндамицин - антибиотик группы линкозамидов [22].

В ряде научных исследований [23-25] опубликованы данные о том, что клиндамицин оказывает бактериостатическое действие, а в высоких концентрациях в отношении некоторых микроорганизмов - бактерицидное, препятствует колонизации сально-волосяного фролликула $P$. acnes, что приводит к уменьшению воспаления. Механизм его действия связан с подавлением синтеза белка в микробной клетке за счет взаимодействия с 50S-субъединицей рибосом. Инактивация бактериальных липаз клинда- 
мицином ведет к снижению концентрации свободных жирных кислот на поверхности кожи, что приводит к уменьшению комедонообразования.

В терапии пациентов с акне применяют клиндамицин в нескольких лекарственных формах (крем, гель, раствор). 1\% раствор является удобным с точки зрения нанесения препарата на элементы сыпи на лице, обширные участки туловища, а также при поражении кожи в зонах роста волос.

Целью настоящего исследования явилась оценка клинической эффрективности и переносимости раствора клиндамицина (1\%) при терапии акне различной степени тяжести.

\section{Материал и методы}

Под наблюдением находились 37 пациентов с акне, тяжесть течения которых определяли с учетом количества комедонов, папул, пустул и узлов. При наличии единичных элементов дерматологический индекс акне оценивали как менее 5 баллов (легкая степень тяжести), при умеренном количестве - 6-15 баллов (средняя степень тяжести), при большом количестве - более 15 баллов.

У 22 (59,5\%) пациентов была диагностирована легкая, у 15 (40,5\%) -средняя степень тяжести. Всем больным был назначен раствор клиндамицина (1\%), который применялся при легкой степени тяжести в виде монотерапии 2 раза в сутки (утром и вечером) точечно на элементы сыпи, а при средней степени тяжести акне - в комбинации с топическими ретиноидами или с бензоила пероксидом, в этом случае раствор клиндамицина - утром, а бензоила пероксид или адапален вечером. Препарат наносился на сухую и чистую кожу. Средний курс лечения составил 6-8 нед.

Эффрективность терапии оценивалась по изменению показателей дерматологического индекса акне через месяц после начала лечения, а также при окончании лечения (на 6-8-й неделе).

\section{Результаты и обсуждение}

Нами были проанализированы объективные и субъективные данные эффективности и безопасности 1\% раствора клиндамицина (препарат Зеркалин), дана оценка динамики клинического течения акне на фоне проводимой терапии, субъективных ощущений пациентов (см. рисунок).

После терапии 1\% раствором клиндамицина было отмечено снижение дерматологического индекса акне более $79 \%$ у 86,3\% пациентов с легкой степенью тяжестью акне, более $72 \%$ - у $60 \%$ пациентов со средней степенью тяжести. Переносимость лечения была отмечена как хорошая у всех пациентов.

По оценке самих пациентов, в 51,3\% случаев переносимость лечения оценивалась как очень хорошая и в $48,7 \%$ - как хорошая. Важным моментом явля-

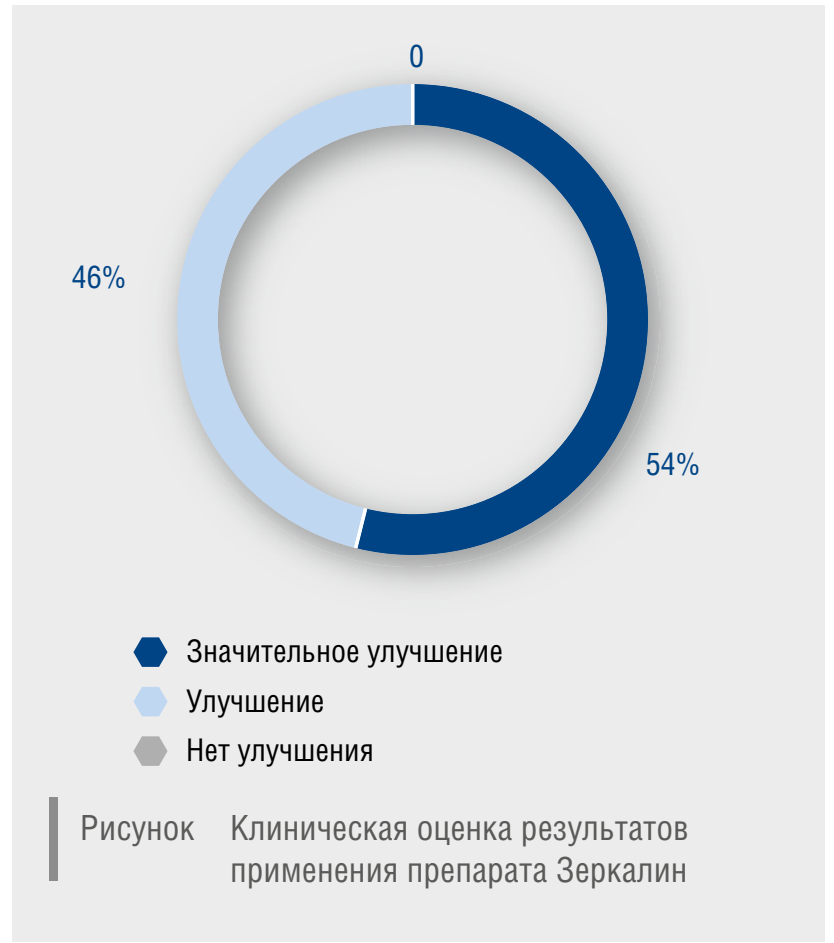

лось отсутствие побочных эфффектов, связанных с увеличенной чувствительностью кожи при воздействии прямых солнечных лучей в весенне-летний период, что соотносится с фрактом отсутствия фротосенсибилизирующего эфффекта клиндамицина [26].

Кроме этого, пациенты отметили удовлетворенность результатами лечения: 25 (67,6\%) полностью удовлетворены, 10 (27\%) удовлетворены, 2 (5,4\%) не полностью удовлетворены.

Одним из показателей эфффективности терапии пациентов с акне является качество жизни пациентов. Исчезновение или уменьшение клинических проявлений акне благоприятно сказывается на общем и психическом состоянии пациента. На фоне терапии отмечено, что с улучшением клинической картины заболевания пропорционально улучшались и показатели качества жизни пациентов.

\section{Выводы}

1. Раствор клиндамицина (1\%) обладает достаточной терапевтической активностью при акне, что подтверждается снижением дерматологического индекса акне на фроне его использования.

2. Зеркалин удобен в применении и хорошо переносится пациентами как при монотерапии, так и в комплексной терапии акне.

3. Раствор клиндамицина (1\%) может успешно применяться в весенне-летний период, когда многие другие препараты для местного лечения акне не могут быть использованы. 


\section{Заключение}

Использование 1\% раствора клиндамицина у $86,3 \%$ пациентов с легкой степенью тяжести акне и у $60 \%$ пациентов со средней степенью тяжести позволило добиться стойкой медикаментозной ремиссии заболевания и значительно улучшить качество их жизни.
Проведенное нами исследование позволяет рекомендовать препарат Зеркалин как безопасное и эфрфективное средство, которое может использоваться в лечении пациентов с акне различной степени тяжести как при монотерапии, так и в комбинации с топическими ретиноидами или с бензоила пероксидом.

\section{Литература}

1. Dréno B. Recent data on epidemiology of acne. Ann Dermatol Venereol 2010; 137(2): 49—51. doi: 10.1016/S0151-9638(10)70024-7.

2. Bhate K., Williams H.C. Epidemiology of acne vulgaris. Br J Dermatol 2013; 168(3): 474485. doi: 10.1111/bjd.12149.

3. Dréno B., Layton A., Zouboulis C.C., LópezEstebaranz J.L., Zalewska-Janowska A., Bagatin E. et al. Adult female acne: a new paradigm. J Eur Acad Dermatol Venereol 2013; 27: 1063-70. doi: 10.1111/jdv.12061.

4. Ghodsi S.Z., Orawa H., Zouboulis C.C. Prevalence, severity, and severity risk factors of acne in high school pupils: a community-based study. J Invest Dermatol 2009; 129(9): 21362141. doi: $10.1038 /$ jid.2009.47.

5. Makrantonaki E., Ganceviciene R., Zouboulis C. An update on the role of the sebaceous gland in the pathogenesis of acne. Dermatoendocrinol 2011; 3(1): 41-49. doi:10.4161.

6. Kircik L.H. Advances in the Understanding of the Pathogenesis of Inflammatory Acne. J Drugs Dermatol 2016; 15(1): 7-10.

7. Arora M.K., Yadav A., Saini V. Role of hormones in acne vulgaris. Clin Biochem. 2011; 44(13): 1035-40. doi: 10.1016

8. Cunha M.G., Fonseca FLA, Machado CDAS. Androgenic Hormone Profile of Adult Women with Acne. Dermatology 2013; 226(2): 167-71. doi: 10.1159/000347196.

9. Schmidt T.H., Shinkai K. Evidence-based approach to cutaneous hyperandrogenism in women. J Am Acad Dermatol 2015; 73(4): 672-90. doi: 10.1016.

10. Del Prete M., Mauriello M.C., Faggiano A., Di Somma C., Monfrecola G., Fabbrocini G., Colao A. Insulin resistance and acne: a new risk factor for men? Endocrine 2012; 42: 555—60. doi: 10.1007/s12020-012-9647-6.
11. Pace J.L. Acne - a potential skin marker of internal disease. Clin Dermatol 2015; 33(5): 572—8. doi: 10.1016/j.clindermatol.2015.05.010.

12. Perry A., Lambert P. Propionibacterium acnes: Infection beyond the skin. Expert Review of Anti-infective Therapy 2011; 9 (12): 1149—56. doi: 10.1586/eri.11.137.

13. Gomes PdeS., Fernandes M.H. Defensins in the oral cavity: distribution and biological role. J Oral Pathol Med 2010; 39(1): 1—9. doi: 10.1111/j.1600-0714.2009.00832.

14. Niyonsaba F., Nagaoka I., Ogawa H., Human defensins and cathelicidins in the skin: beyond direct antimicrobial properties. Crit. Rev. Immunol 2006; 26(6): 545—76.

15. Ozlu E., Karadag A.S., Ozkanli S., Oguztuzun S., Kilic M., Zemheri E et al Comparison of TLR-2, TLR-4, and antimicrobial peptide levels in different lesions of acne vulgaris. Cutan Ocul Toxicol 2015; (23):1-10. doi: 10.3109/15569527.2015.1120742.

16. Kim M.K., Choi S.Y., Byun H.J., Huh C.H., Park K.C., Patel R.A. et al. Comparison of sebum secretion, skin type, pH in humans with and without acne. Arch Dermatol 2006; 298(3):113—9.

17. Schauber J., Gallo R.L. Expanding the roles of antimicrobial peptides in skin: alarming and arming keratinocytes. J Invest Dermatol 2007; 127(3): 510-2.

18. Pashinyan A.G. Modern methods of therapy of an acne. Medical Council 2010;(5-6): 61-62 [Пашинян А.Г. Современные методы терапии акне. Медицинский Совет 2010; (5-6): 61-62].

19. Zaenglein A.L., Pathy A.L., Schlosser B.J. Alikhan A., Baldwin H.E., Berson D.S. et al. Guidelines of care for the management of acne vulgaris. J Am Acad Dermatol 2016; 74(5): 945-73. doi: 10.1016/j.jaad.2015.12.037.
20. Savage L.J., Layton A.M. Treating acne vulgaris: systemic, local and combination therapy. Expert Rev Clin Pharmacol 2010; 13: 563580. doi: 10.1586/ecp.10.27.

21. Kubanova A.A., Kubanov A.A., Samzov V.A., Araviiskaia E.A. Federalnyie klinicheskie rekomendatsii po vedeniyu bolnyih akne. Rossiyskoe obschestvo dermatovenerologov i kosmetologov. М., 2016; 9-27. [Кубанова А.А., Кубанов А.А., Самцов А.В., Аравийская Е.Р. Федеральные клинические рекомендации по ведению больных акне. Российское общество дерматовенерологов и косметологов. М., 2016; 9-27].

22. Kanliff V.Dzh. Akne. V kn: Katsambas A.D., Lotti T. M. (red.) Evropeyskoye rukovodstvo po lecheniyu dermatologicheskikh zabolevaniy: Per. s angl. M.: MEDpress-inform. 2008; 19—24. [Канлиффф В.Дж. Акне. В кн: Кацамбас А. Д. Лотти Т.М. (ред.) Европейское руководство по лечению дерматологических заболеваний: Пер. с англ. М: МЕДпресс-инсормм, 2008; 19-24.]

23. Del Rosso J.Q., Schmidt N.F. A review of the antiinflammatory properties of clindamycin in the treatment of acne vulgaris. Cutis. 2010; 85(1):15-24.

24. Alirezaï M., Gerlach B., Horvath A., Forsea D., Briantais P., Guyomar M. Results of a randomised, multicentre study comparing a new water-based gel of clindamycin $1 \%$ versus clindamycin $1 \%$ topical solution in the treatment of acne vulgaris. Eur J Dermatol 2005; 15(4): 274—8.

25. Guay D.R. Topical clindamycin in the management of acne vulgaris. Expert Opin Pharmacother 2007; 8(15): 2625-64.

26. Monakhov S.A. Clindamycinsolution (1\%) in thetherapy of acne. Klin Dermatol Venerol 2012; (5): 85-88 [Монахов С.А. Раствор клиндамицина (1\%) в терапии акне. Клин дерматол и венерол 2012; (5): 85-88].

об авторах:

А. Г. Пашинян — д.М.Н., профрессор кафедры дерматовенерологии лечебного факультета ФГБОУ ВО РНИМУ им. Н. И. Пирогова Минздрава России, Москва

А. А. Шахнович — к.м.Н., зав. дерматологическим отделением ФГБУ «Поликлиника № 5» Управления делами Президента Российской Федерации, Москва

\section{Конфликт интересов}

Авторы заявляют об отсутствии потенциального конфрликта интересов, требующего раскрытия в данной статье 